\title{
Microwave Assisted Calcination of Colemanite Powders
}

\author{
M. Fatih Can ${ }^{1}$, Ahmet Helvaci², Ziya Ozgur Yazici ${ }^{3 *}$, Süleyman Akpınar ${ }^{3}$ and Yusuf Özdemir ${ }^{3}$ \\ ${ }^{1}$ Department of Mining Engineering, Afyon Kocatepe University, 03200, Turkey \\ ${ }^{2}$ Department of Chemical Engineering, Afyon Kocatepe University, Afyonkarahisar, 03200, Turkey \\ ${ }^{3}$ Department of Materials Science and Engineering, Afyon Kocatepe University, Afyonkarahisar, 03200, Turkey
}

\begin{abstract}
In this study, the possibility of using colemanite mineral $\left(2 \mathrm{CaO} .3 \mathrm{~B}_{2} \mathrm{O}_{3} .5 \mathrm{H}_{2} \mathrm{O}\right)$ which cannot be used directly as an additive for fast firing ceramic bodies due to execution of its crystal water through the micropores, was examined after microwave-assisted calcination. For this purpose, domestic microwave oven which was modified with fiber boards, $\mathrm{SiC}$ susceptors and thermocouple setup was used. Colemanite powders heat-treated in a porcelain crucible under microwave condition with three different power levels of 385, 539 and $700 \mathrm{~W}$. Temperature profiles of samples were defined as a function of time and calcination states were determined by confirming volumetric expansion and weight loss. When findings were systematically evaluated by X-ray diffraction (XRD) and thermal analysis (DTA/TG), surface area (BET), volume expansion analysis, the results were in favor of microwave-assisted calcination than conventional one in terms of efficiency for both time and temperature of heat treatments.
\end{abstract}

\section{Publication History:}

Received: December 02, 2016

Accepted: December 20, 2016

Published: December 22, 2016

\section{Keywords:}

Calcination, Colemanite,

Microwave, Energy

\section{Introduction}

Boron, the fifth element in the periodic table, does not occur in nature in its elemental form. Rather, boron combines with oxygen as a salt or ester of boric acid. There are more than 200 minerals that contain boric oxide but relatively few that are of commercial significance [1]. Boron minerals are differently named regarding to their alkali, earth alkali, boron oxide $\left(\mathrm{B}_{2} \mathrm{O}_{3}\right)$ and water contents and crystal structures [2]. In fact, three minerals represent almost $90 \%$ of the borates used by industry: borax (tincal), a sodium borate; ulexite, a sodium-calcium borate; and colemanite, a calcium borate [1].

Turkey is the largest producer of natural borates worldwide. Boron reserves are highly concentrated in Turkey, which accounts for around $70 \%$ of the world total. The Turkish borate deposits occur in western Anatolia in five main districts; Bigadic, Kestelek, Sultancayiri, Emet, and Kirka. The borates in Turkey are tincal, colemanite and ulexite. Colemanite reserves have the largest share (73.9\%) compared to tincal (24.5\%) and ulexite (1.6\%). Colemanite and tincal are the most widely-used boron minerals. $\mathrm{B}_{2} \mathrm{O}_{3}$ wt. percentages of the minerals are $50.8 \%$ and $36.5 \%$, respectively. Nearly $10 \%$ of the natural borates are consumed as it is; whereas the rest is used to produce refined products [3].

Boron oxide-bearing minerals can technologically be considered as important alternative raw materials since they have a glass-forming character and have been used in the ceramic industry to reduce the melting point, lower the viscosity and decrease the CLTE of the glass phase and therefore raise its heat-resistance, and increase the mechanical strength and chemical stability of the materials [45]. Presently, borates, especially colemanite, find a wide variety of applications in industry [6]. Colemanite is a hydrated calcium borate $\mathrm{Ca}_{2} \mathrm{~B}_{6} \mathrm{O}_{11} .5 \mathrm{H}_{2} \mathrm{O}$ with crystalline structure of complex chains of tetrahedral $\mathrm{B}(\mathrm{O}, \mathrm{OH})_{4}$ and triangles $\mathrm{BO}_{3}$, bound into a triangular structure via the ions $\mathrm{Ca}^{2+}$ and buffer molecules $\mathrm{H}_{2} \mathrm{O}$ [5]. Colemanite is an industrially important mineral, which is mostly used in textile type fiberglass, glass and ceramic industries and metallurgy. Colemanite is also used in detergent and cosmetic industries and for production of boric acid by reacting with sulfuric acid. When used in textile type fiberglass industry, colemanite drops the melting temperature of the mixture, provides low viscosity at the melting temperature, prevents crystallization and positively affects the chemical and physical properties of final glass product. Colemanite reduces the melting point in glass industry and it is resistant to thermal shocks. In formulation of ceramic and enamel glazes, it provides a stable structure, homogeneous melting and low segregation. Since it is a solvent for almost all metal oxides, it is used as a fluxing agent in the metallurgy industry [7].

When boron minerals are heated, the mineral first loses water of crystallization, followed by production of amorphous material or recrystallization into new phases [8]. The decomposition process of colemanite mineral exhibits intra-crystalline thermal dissociation. While formation of the water molecules from the $\mathrm{OH}$ groups in the structure take place, water molecules which have been formed by this step, released by the heating energy. Two stages of this dissociation events are proceed uniformly within the crystal grains of the mineral. Waclawska et al. (1998) report that colemanite structure involves enclosed water molecules within the structure and the pressure of the enclosed $\mathrm{H}_{2} \mathrm{O}$ molecules increases rapidly that cause an explosive water loss with increasing temperature [9]. This sudden release within the micropores induces a disruption of the framework by increment of the temperature [8-9]. For this reason, direct use of colemanite mineral is limited as a raw material in ceramic industry. The other issue is that deformation problems will be observed in the final products if boron containing minerals are used with high amounts in ceramic products when they preferred to densify in fast firing process [10]. Therefore, colemanite mineral should be calcined in order to prevent such problems before usage for sintering aid.

"Corresponding Author: Dr. Ziya Ozgur Yazici, Department of Materials Science and Engineering, Afyon Kocatepe University, Afyonkarahisar, 03200, Turkey, Tel: +90 272 2281423; Fax: +90 272 2281422; E-mail: zyazici@aku.edu.tr

Citation: Can MF, Helvaci A, Yazici ZO, Akpınar S, Özdemir Y (2016) Microwave Assisted Calcination of Colemanite Powders . Int J Metall Mater Eng 2: 129. doi: https://doi.org/10.15344/2455-2372/2016/129

Copyright: (C) 2016 Can et al. This is an open-access article distributed under the terms of the Creative Commons Attribution License, which permits unrestricted use, distribution, and reproduction in any medium, provided the original author and source are credited. 
Decomposition of colemanite by conventionally should be performed with very slow heating rates in order to avoid harmful effects of the severe water release within micropores of colemanite. Unfortunately, slow heating rates bring very long processing durations and cause slower production rates and high costs. At this point, microwave heating process is a technology that can provide fast heat generation within the body and shorter process duration. Since microwave heating process provides rapid heating of materials without overheating the surface, removal of water vapour from materials can be smooth without cracking. It is therefore possible to use in calcination process by microwave heating, in a fraction of the time that it takes for conventional heating. The difficulty to coupling microwave and material at low temperatures can be improved with the help of a hybrid heating scheme that combines microwave and convective heating by the use of susceptors to bring the temperature of the material to its critical microwave coupling temperature (microwave assisted heating) [11]. Therefore, it is thought to be an alternative approach use of microwave energy instead of conventional method in the calcination process. The purpose of this research is to compare of both conventional and microwave techniques on the calcination of colemanite and to explore the advantages of microwave heating on the process duration and temperature. If this aim is made possible, then the ceramic industry will benefit by having a new and cheaper raw material.

\section{Experimental Procedure}

The ground colemanite under 75 micron used in this study was provided from Eti Mine in Turkey. Comparison of both conventional and microwave techniques on the calcination of colemanite were performed. In conventional calcination studies, colemanite samples were heated to 450 and $700^{\circ} \mathrm{C}$ with a heating rate of $10^{\circ} \mathrm{C} / \mathrm{min}$. The temperatures were selected in an interval between release of crystal water and the beginning of the amorphization behavior, which are determined by the results of DTA-TG analysis of colemanite powder. In microwave calcination studies, colemanite samples were heated to the same temperatures by using a modified domestic microwave oven with different power levels $(385,539$ and $700 \mathrm{~W})$ in order to determine optimal power level in calcination process. Modification of domestic microwave oven described as follows; silicon carbide susceptors were used for initial heating of the samples which are insensitive to microwave radiation. Porous fiberboard cubic box of $10 \mathrm{~cm}^{3}$ was used as thermal insulation (so-called thermal box) to maintain temperature increase for calcination process and also to protect the internal chamber of the microwave oven. Two half-moon shaped $\mathrm{SiC}$ susceptors were placed in a symmetrically configuration within the box, and the material to be processed in a crucible is placed in the central position of the susceptors. The entire thermal box was then placed in the chamber of microwave oven for processing. The temperature of the samples was monitored using a thermocouple

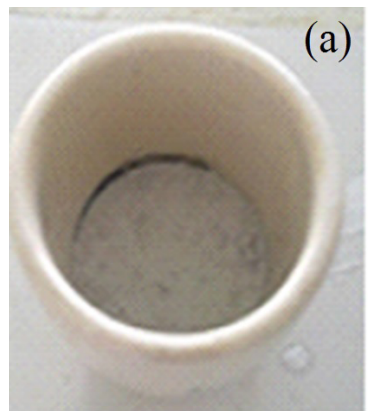

(a)
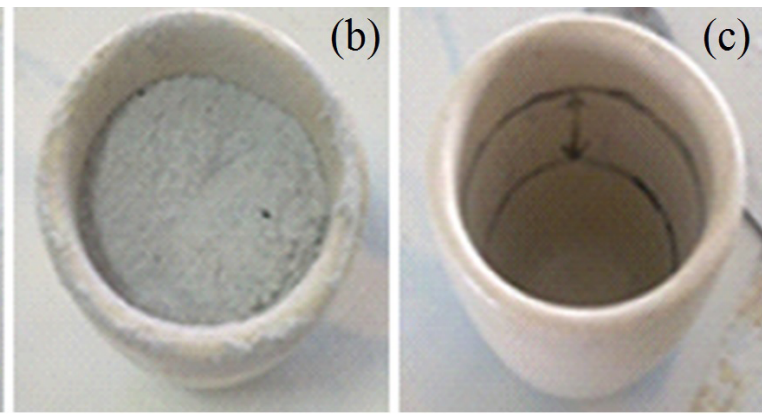

(c)

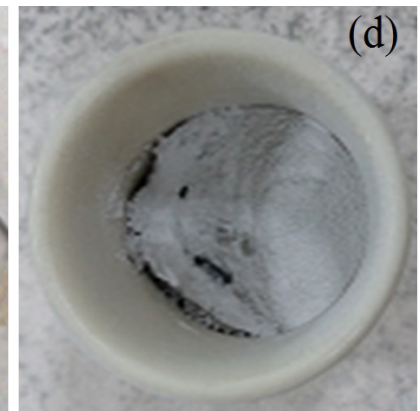

Figure 1: (a-c) Calculation of volumetric expansion (d) calcined colemanite at $595^{\circ} \mathrm{C}$ by microwave assisted heating.

Int J Metall Mater Eng

ISSN: 2455-2372

IJMME, an open access journal Volume 2. 2016. 129
(TP-01 Type K) setup coupled with a data logger and thermocouple probe was inserted to the center of the crucible. Calcination of colemanite powders were carried out at different power levels as a function of time. By this way, temperature-time profiles for each power levels were observed for the setup.

Thermal behavior of colemanite samples for conventional heating was carried out using a Netzsch STA 449 differential thermal analyzer with a thermogravimetric analyzer (DTA-TG) at $10^{\circ} \mathrm{C} / \mathrm{min}$ in air atmosphere. Thermal behavior of colemanite samples for microwave assisted heating was evaluated by volumetric and mass changes (Figure 1) at different temperatures $\left(450-600^{\circ} \mathrm{C}\right)$. X-ray diffraction (XRD) analysis was performed by a Bruker-D8 Advance type X-ray phases in the raw and calcined states of the samples. Characterizations of surface area, pore size and pore volumes of the calcined samples were evaluated by BET (Brunauer-Emmett-Teller) analysis.

\section{Results and Discussion}

Temperature vs time graphics for different power levels; medium $(385 \mathrm{~W})$, high $(539 \mathrm{~W})$, very high $(700 \mathrm{~W})$ of modified domestic microwave oven is shown in Figure 2a. Temperature measurements were verified by three different measurements. It can be clearly seen that microwave-assisted heating supply very close temperature fluctuations within the same power groups. According to these data,it can be said that $700 \mathrm{~W}$ and $539 \mathrm{~W}$ microwave power levels require approximately same time to reach the same temperature, whilst 385 W power level needs more. For this reason, high level $(539 \mathrm{~W})$ was determined as optimal power level in this study in order to save time as well as energy. Also, microwave-assisted heating can offer significant time savings compared to conventional heating as indicated in Figure $2 \mathrm{~b}$. The further studies in microwave calcination process were carried out in the range from $450^{\circ} \mathrm{C}$ to $700^{\circ} \mathrm{C}$; a five minute standing period at these temperatures in high power level (539 Watt). \% weight loss $(\Delta \mathrm{m})$ and $\%$ volumetric expansion $(\Delta \mathrm{v})$ values of calcined colemanite at different temperatures are listed in Table 1 where both $\Delta \mathrm{m}$ and $\Delta \mathrm{v}$ values (\%) are trending with the increase of temperature. A volumetric expansion of $70 \%$ in the sample at $450^{\circ} \mathrm{C}$ was observed and it has reached up to $80 \%$ with increase in temperature and ended by partial melting of colemanite at $595^{\circ} \mathrm{C}$ in microwave assisted calcination (Figure 1d).

\begin{tabular}{|c|c|c|}
\hline Temperature $\left({ }^{\circ} \mathrm{C}\right)$ & Weight Loss $(\%)$ & Volumetric Expansion(\%) \\
\hline 450 & 10 & 70 \\
\hline 500 & 12 & 75 \\
\hline 550 & 16 & 80 \\
\hline 595 & 22 & - \\
\hline
\end{tabular}

Table 1: \%Weight loss and \%volumetric expansion of colemanite at different temperatures (microwave calcination). diffractometer using $\mathrm{Cu} \mathrm{Ka}$ radiation to identify the present crystalline 

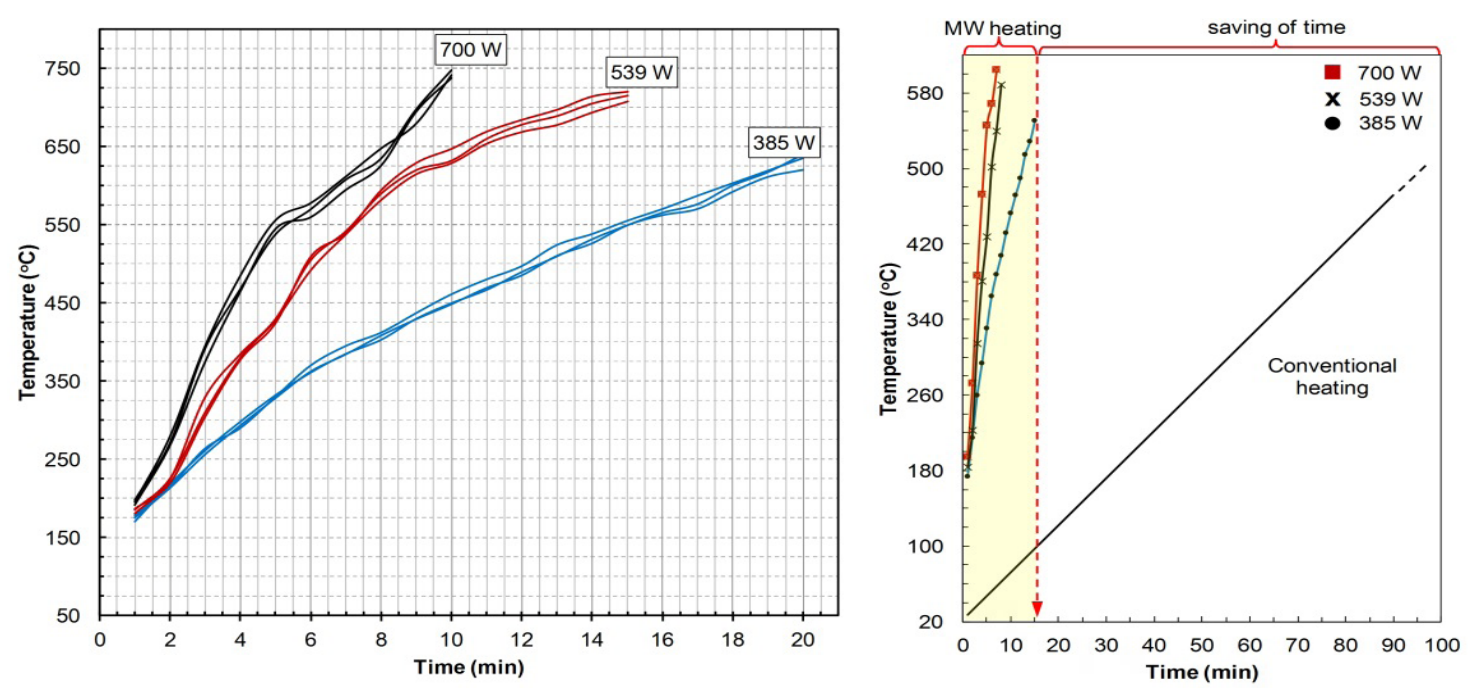

Figure 2: (a)Verification of temperature-time plots for different power levels and (b) comparison of conventional.

Surface area, pore size and pore volume values of colemanite heattreated at different temperatures by microwave and conventional heating techniques are presented in Table 2. Elevated temperatures result in reduction of the surface area values of calcined forms. It was also observed that the pore size of the heat-treated samples enlarged compared to raw state of the colemanite. Furthermore, pore size values significantly increased after the calcination by both of microwave and conventional heating techniques at $450^{\circ} \mathrm{C}$. Due to softening effect, this value plainly decline with higher calcination temperatures. When the samples calcined at $450^{\circ} \mathrm{C}$ were compared according to the heating technique, it is clearly seen that microwave-heated samples exhibits lower surface area and higher pore size and pore volume values than those of conventional calcined samples. A volumetric expansion of $70 \%$ with the increase in the pore size of calcined sample at $450^{\circ} \mathrm{C}$ also confirm the pressure of the enclosed water molecules increases so much that it disrupts the framework and they are released.

\begin{tabular}{|l|l|l|l|}
\hline Samples & $\begin{array}{l}\text { Surface area } \\
\left(\mathrm{m}^{2} / \mathrm{g}\right)\end{array}$ & Pore size $(\mathrm{nm})$ & $\begin{array}{l}\text { Pore volume } \\
\left(\mathrm{cm}^{3} / \mathrm{g}\right)\end{array}$ \\
\hline Raw colemanite & 6.48 & 8.33 & 0.0135 \\
\hline $\begin{array}{l}\text { Conventional } \\
\text { calcined }\left(450^{\circ} \mathrm{C}\right)\end{array}$ & 3.81 & 16.02 & 0.0153 \\
\hline $\begin{array}{l}\text { Microwave } \\
\text { calcined }\left(450^{\circ} \mathrm{C}\right)\end{array}$ & 3.51 & 18.16 & 0.0159 \\
\hline $\begin{array}{l}\text { Conventional } \\
\text { calcined }\left(700^{\circ} \mathrm{C}\right)\end{array}$ & 3.10 & 14.43 & 0.0112 \\
\hline $\begin{array}{l}\text { Microwave } \\
\text { calcined }\left(595^{\circ} \mathrm{C}\right)\end{array}$ & 3.46 & 9.21 & 0.0080 \\
\hline
\end{tabular}

Table 2: Surface area, pore size and pore volume values of colemanite samples.

Thermal analysis of colemanite was studied by many researchers. Waclawska et al. proposed that colemanite decomposes in two mechanisms: (1) formation of $\mathrm{H}_{2} \mathrm{O}$ from $\mathrm{OH}$ groups and (2) breaking of $\mathrm{H}_{2} \mathrm{O}$ and borate chains bonds and then removal of both kinds of water from the anhydrous phase of the preserved borate structure [9]. DTA curves for raw colemanite samples examined under the standard conditions show two endothermic peaks within the temperature range $325-440^{\circ} \mathrm{C}$ (Figure 3). The first one is at $384^{\circ} \mathrm{C}$ and starts a distinct inflection at $360^{\circ} \mathrm{C}$. This first event means that the thermal dissociation of colemanite begins with the removal of the $\mathrm{OH}$ groups, which form water molecules. Next, the bonds of molecular water with borate rings become broken. This can be judged from the endothermic peak at $398^{\circ} \mathrm{C}$. According to Waclawska et al., this endothermic reaction is accompanied by disintegration of the sample into small particles and their spraying [9]. In addition, heat microscopy studies by Wacklawska have shown that this process has a sudden and explosive character [9]. Next, the removal of water proceeds rapidly up to approximately $440^{\circ} \mathrm{C}$ as observed from the TG curve. The peaks at $384^{\circ} \mathrm{C}$ and $398^{\circ} \mathrm{C}$ are accompanied by a 10.23 wt.\% loss due to the release of water. The water content in the colemanite sample examined lower than that of theoretically calculated (21.84 wt. \%) is the result of the presence of calcite in its crystal structure as will be seen in XRD results below. The remaining water release slowly up to $600^{\circ} \mathrm{C}$. At a temperature of $751^{\circ} \mathrm{C}$ there occurs an exothermic peak accompanied by change of $4.8 \mathrm{wt} . \%$ in the weight of the sample, preceded by a weak endothermic peak $\left(662^{\circ} \mathrm{C}\right)$. Characteristics of DTA trace indicates that it is caused by an exothermic crystallization $\left(751^{\circ} \mathrm{C}\right)$ below the melting point of the compound $\left(950^{\circ} \mathrm{C}\right)$. These observations are comparable with those of Waclawska [9].

A weight loss of $10 \%$ in the sample at $450^{\circ} \mathrm{C}$ observed in the microwave calcination (Table 1) was found to overlap with the weight loss at the same temperature in the DTA-TG analysis. Besides, the weight loss is determined as $23 \%$ in the DTA-TG analysis until $800^{\circ} \mathrm{C}$ was found to occur in the microwave-assisted calcination up to $595^{\circ} \mathrm{C}$.

To understand the nature of the processes that have occurred after heating, an X-ray analysis of the raw colemanite and the colemanite samples heat-treated at different temperatures were performed (Figure 4). The investigations showed that the initial raw form consists primarily of the mineral colemanite with a significant amount of calcite $\left(\mathrm{CaCO}_{3}\right)$. Moreover, during heat treatment, the structure of colemanite is exposed to a series of transformations including dehydroxylation and dehydration up to $450^{\circ} \mathrm{C}$ as seen in DTG analysis curve. It is seen that this disintegration reaction is accompanied by approximately $10 \mathrm{wt}$. \% loss in TG analysis. It is understood that disintegration of colemanite occurred also in microwave heating through the similar weight loss was observed by conventional calcination at the same temperature. Furthermore, Table 2 shows that the pore size value by both heating routes at this temperature has a considerable change and there is an enlargement in the pore size by disintegration reaction. 


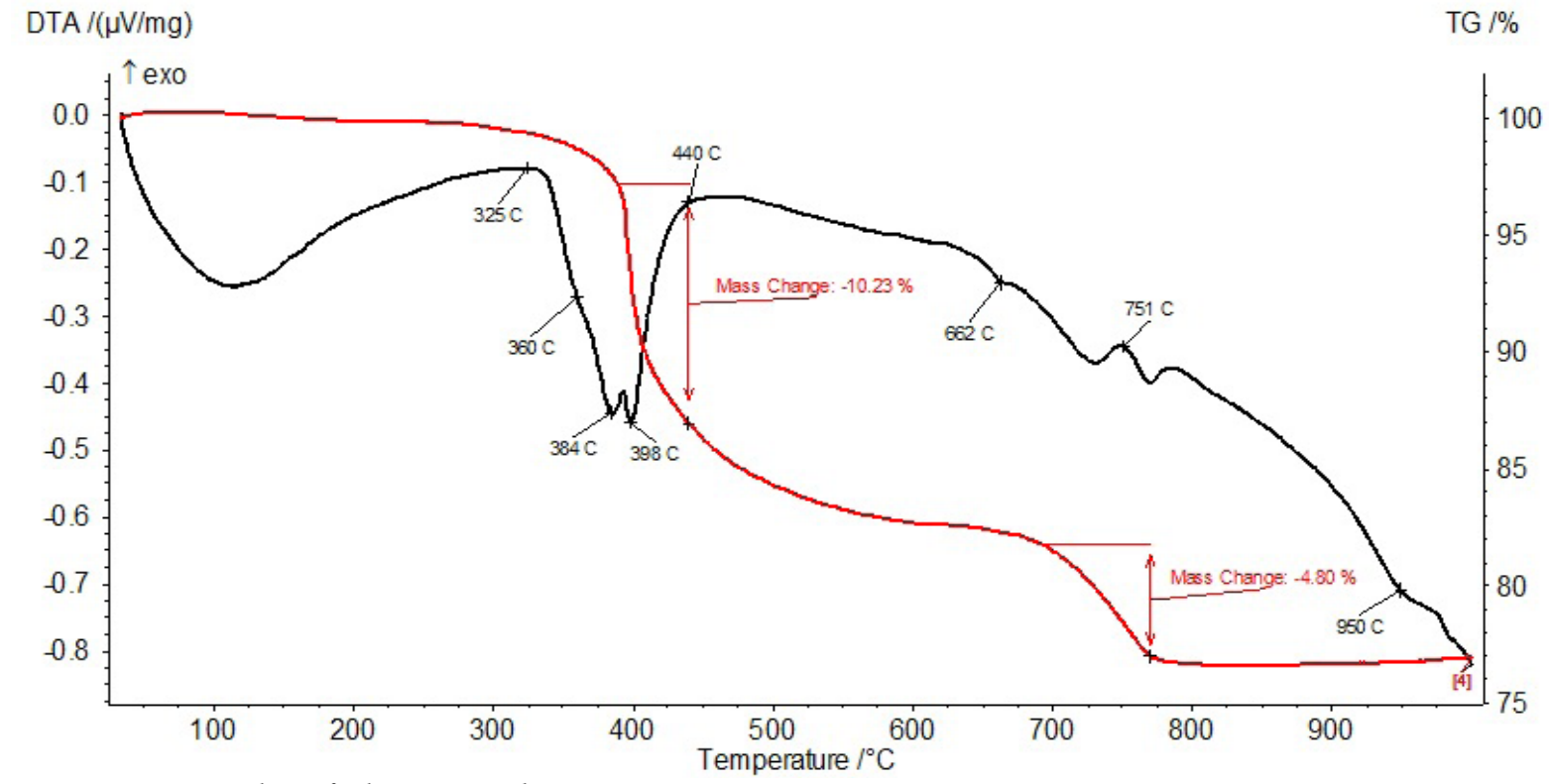

Figure 3: DTA-TG analysis of colemanite powder.

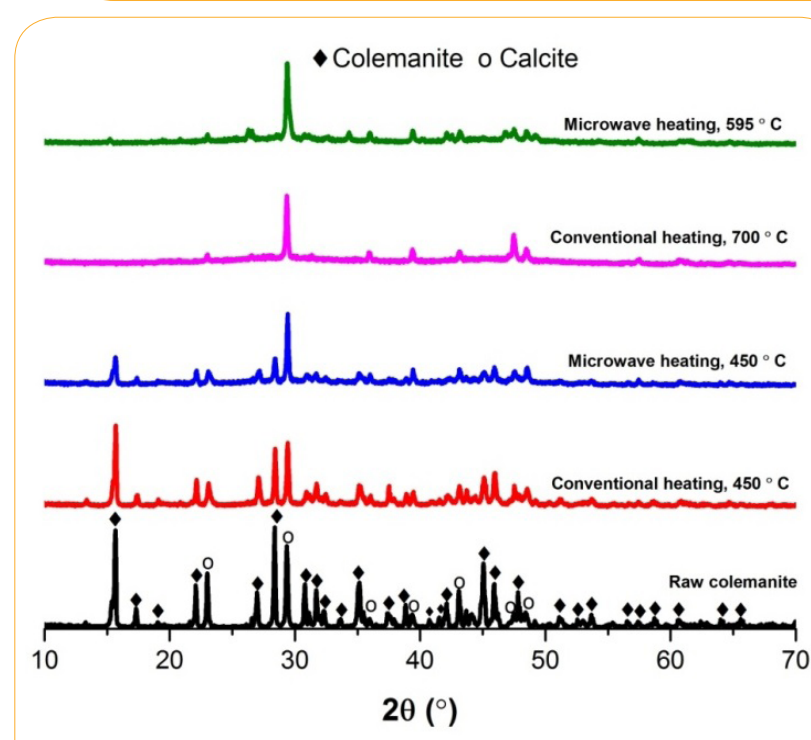

Figure 4: XRD patterns of the samples obtained through conventional and microwave assisted heating.

According to our experiences the XRD patterns of powders after conventional and microwave-assisted calcination at $450^{\circ} \mathrm{C}$ is crucial.

At the stated temperature, although a significant change at phase structure was not observed compared with raw material, a decrease at peak intensity was determined. This supports that colemanite forms only decomposition reaction with the conventional and microwaveassisted calcination at $450^{\circ} \mathrm{C}$. It was seen in Figure $1 \mathrm{~d}$ that at $595^{\circ} \mathrm{C}$ in microwave-assisted calcination, colemanite begins to melt partially and powders change into the compact state through hardening. For the XRD analysis made at that temperature it is observed that peaks belonging to colemanite lose almost completely and only the peaks belonging to calcite remain, phase structure changes with the calcination at the stated conditions. It can be understood that colemanite is decomposed to $\mathrm{B}_{2} \mathrm{O}_{3}$ and $\mathrm{CaO}$ in their amorphous forms and calcite upon calcination. As a result of the observations, it is determined that partial melting occurs at $700^{\circ} \mathrm{C}$ at conventional heating process while it occurs at $595^{\circ} \mathrm{C}$ by microwave assisted heating. It is found out that XRD investigations at starting temperature of partial melting by both heating routes are similar. This situation shows that microwave assisted calcination provides an advantage as about $100^{\circ} \mathrm{C}$ decrease at the transition temperature of colemanite into amorphous calcium borate and crystal calcite.

During the preliminary experiments of this research performed without susceptors and under direct microwave heating, thermal runaway characteristics of colemanite was observed at $539 \mathrm{~W}$ for 10 minute condition as material fully liquidified in crucible. Therefore our systematic studies with susceptors system revealed that the shortest period of calcination is performed at $450^{\circ} \mathrm{C}$ for 10 minutes periods which is obviously $100^{\circ} \mathrm{C}$ lower that melting point.

\section{Conclusion}

The advantages of microwave heating on the process period and temperature was investigated through both convetional and microwave techniques for calcination of colemanite. Structural properties of asreceived colemanite and heat treated powders were characterized by XRD, DTA-TG and BET analyses and thermal behavior of colemanite for microwave assisted heating was evaluated by volumetric and mass changes. Besides the major colemanite mineral, calcite also the other main mineral in the powder was detected in XRD analysis. During the decomposition of colemanite, the $\mathrm{OH}$ groups are the first to break off from the borate anions (dehydroxylation) and the water molecules split off (dehydration) within the temperature interval $325-440^{\circ} \mathrm{C}$. A volumetric expansion of $70 \%$ with the increase in the pore size of the calcined sample at $450^{\circ} \mathrm{C}$ confirm the pressure of the enclosed water molecules increases so much that it disrupts the framework and they are released. Characterization results are revealed that microwave assisted calcinations provides an advantage as process time the lowest calcination temperature to be $450^{\circ} \mathrm{C}$ as 10 minutes and in terms of a $100{ }^{\circ} \mathrm{C}$ reduction of the transition temperature of colemanite into amorphous calcium borate and crystal calcite. 
Citation: Can MF, Helvaci A, Yazici ZO, Akpınar S, Özdemir Y (2016) Microwave Assisted Calcination of Colemanite Powders . Int J Metall Mater Eng 2: 129. doi: https://doi.org/10.15344/2455-2372/2016/129

Page 5 of 5

\section{Competing Interests}

The authors declare that they have no competing interests.

\section{Funding}

This research was supported by the by Afyon Kocatepe University Scientific Research Project (Project No: 15.MUH.10).

\section{References}

1. Briggs M, Kirk-Othmer Encyclopedia of Chemical Technology (2001) Vol. 4, Boron Oxides, Boric Acid, and Borates, John Wiley \& Sons, Inc.

2. Karasu B, Yurdakul H, Kaya G (2004) Use of borax solid wastes in wall tile body recipes as a fluxing agent and it's effects on microstructure, Seramik, October-December, 135-145.

3. Celik AG, Cakal GO (2016) Characterization of espey colemanite and variation of its physical properties with temperature. Physicochem Probl Miner Process 52. 66-76.

4. Ediz N, Yurdakul H (2009) Characterization of porcelain tile bodies with colemanite waste added as a new sintering agent. Journal of Ceramic Processing Research 10: 414-422.

5. Kichkailo OV, Levitskii IA (2011) Effect of Colemanite Additions on Sintering, Properties, and Microstructure of Spodumene Heatproof Ceramic. Glass and Ceramics 68: 56-60.

6. Yildiz Ö (2004) The effect of heat treatment on colemanite processing: a ceramics application. Powder Technology 142: 7-12.

7. Eti Mine (2014) Espey Colemanite, Product Data Sheet, Ankara.

8. Eymir Ç, Okur H (2005) Dehydration of ulexite by microwave heating Thermochimica Acta 428: 125-129.

9. Waclawska I, Stoch L, Paulik J, Paulik F (1988) Thermal Decomposition of Colemanite. Thermochimica Acta 126: 307-318.

10. Ediz N, Yurdakul H (2009) Development of body formulations using colemanite waste in porcelain tile production. Journal of Ceramic Processing Research 10: 758-769.

11. Akpınar S, Kuşoğlu IM, Ertugrul O, Onel K (2015) Microwave assisted sintering of in-situ cordierite foam, Ceramics International 41: 8605-8613. 